Hal. $240-251$

\title{
KOMPARASI MODEL PENGARUH KUALITAS LAYANAN TERHADAP KEPUASAN DAN LOYALITAS DEBITUR KUPEDES BRI BANGSALSARI BERDASARKAN SUKU
}

\author{
Imam Tauhid \\ Fakultas Ekonomi dan Bisnis Universitas Jember \\ tauhid.imam20@gmail.com
}

\begin{abstract}
This study compares the usage models of Kupedes credit of Bank Rakyat Indonesia (BRI) Bangsalsari Jember, between the Javanese and Madurese debtors by analyzing the effect of service quality on satisfaction and loyalty of the debtors. The population is all Kupedes debtors of Javanese and Madurese in BRI Bangsalsari Jember. The sample consists of 120 Javanese debtors and 120 Madurese debtors taken by cluster sampling, purposive sampling, and quota sampling methods. The compared models were analyzed by Structural Equation Modeling (SEM) and comparative test of the two models. The results show that for the Javanese debtors, service quality has no effect on satisfaction, service quality significantly affects loyalty, and satisfaction significantly affects loyalty. For the Madurese debtors, service quality has no effect on satisfaction, service quality has no effect on loyalty, and satisfaction significantly affects loyalty.
\end{abstract}

Keywords: Service Quality, Debtor Satisfaction, Debtor Loyalty

\begin{abstract}
Abstrak: Penelitian ini mengkomparasi model penggunaan produk pinjaman Kupedes di Bank Rakyat Indonesia (BRI) unit Bangsalsari Jember pada debitur suku Jawa dan suku Madura yang didasari pada pengaruh kualitas layanan terhadap kepuasan dan loyalitas debitur. Populasi penelitian adalah seluruh debitur Kupedes suku Jawa dan Madura BRI unit Bangsalsari. Sampel pada penelitian ini terdiri dari 120 responden suku Jawa dan 120 responden suku Madura, yang diambil mengunakan metode cluster sampling, purposive sampling, dan kuota sampling. Model dianalisis dengan permodelan persamaan struktural (SEM) dan uji komparasi dua model. Hasil penelitian menunjukkan bahwa pada suku Jawa, kualitas layanan tidak mempengaruhi kepuasan debitur, kualitas layanan mempengaruhi loyalitas debitur secara signifikan, dan kepuasan debitur secara signifikan mempengaruhi loyalitas debitur. Pada suku Madura, kualitas layanan tidak mempengaruhi kepuasan debitur, kualitas layanan tidak mempengaruhi loyalitas debitur, dan kepuasan debitur secara signifikan mempengaruhi loyalitas debitur.
\end{abstract}

Kata Kunci: Kualitas Layanan, Kepuasan Debitur, Loyalitas Debitur.

\section{Pendahuluan}

Perusahaan jasa khususnya perbankan melakukan beberapa gebrakan dalam bisnisnya. Hal ini karena Bank Indonesia selaku regulator mengeluarkan kebijakan terkait dengan Peraturan Bank Indonesia (PBI) Nomor 2/27/2000 tentang bank umum untuk mendorong bank bisa lebih fokus dalam ekspansi dalam mengembangkan bisinisnya (BI, 2008). Salah satu perbankan yang masih terus eksis menyalurkan produk kredit adalah Bank Rakyat Indonesia (BRI), yang merupakan salah satu bank yang terbesar di Indonesia dengan fokus utama pada bisnis kredit mikro. Kupedes merupakan kredit yang bersifat umum, individual, selektif, dan 
berbunga kisaran $1 \%$ sampai dengan $1,6 \%$ perbulan flat yang bertujuan meningkatkan usaha mikro yang layak. Penelitian yang dilakukan di kecamatan Bangsalsari, Kabupaten Jember, Provinsi Jawa Timur yang terkenal dengan daerah pandalungan yaitu kabupaten yang berada di daerah tapal kuda, daerah yang mayoritas penduduknya suku Jawa dan Madura.

Dalam upaya mempertahankan debitur Bank Rakyat Indonesia khususnya di sektor kredit, perlu ditingkatkan kualitas layanan untuk melayani dan memenuhi kepuasan debitur. Penelitian terdahulu model dan rumusan model penelitian ini merujuk pada beberapa hasil penelitian yaitu Oliver (1999); Lyon and Powers (2004), menyatakan bahwa kualitas layanan merupakan salah satu kunci yang dijadikan pertimbangan kepuasan konsumen, selanjutnya konsumen yang merasa puas akan melakukan pemakaian jasa ulang atau pengulangan selanjutnya debitur tersebut akan bersedia untuk merekomendasikan kepada orang lain.Namun sejumlah studi seperti (Bloemer,et al.1998); Bontis and Booker (2007) dari hasil penelitianya menunjukkan bahwa kualitas layanan tidak berpengaruh signifikan terhadap loyalitas pelanggan.

Kualitas layanan didefinisikan sebagai penilaian dari attitude secara global yang berkaitan dengan superioritas dan layanan, serta. Parasuraman (1988), mengkategorikan beberapa dimensi yang digunakan untuk mengukur kualitas layanan khususnya dalam bidang perbankan adalah (1) reliability, (2) emphaty, (3) efisiensi, (4) prosedur, (5) assurance, (6) responsive. Menurut Parasuraman (1988b), kualitas pelayanan khususnya disektor jasa, tingkat keunggulan yang diharapkan dan pengendalian atas tingkat keunggulan tersebut untuk memenuhi keingginan pelanggan.

Kepuasan pelanggan adalah suatu tingkat perbedaan atau ketidak cocokan antara kinerja produk yang dirasakan dibandingkan dengan kinerja produk atau jasa yang diharapkan. Kepuasan pelanggan timbul dari adanya respon emosional terhadap produk yang digunakan, khususnya ketika mereka membandingkan kinerja yang dirasakan dibandingkan dengan harapannya.Pratiwi dan Asih (2010) menyatakan kepuasan pelanggan dapat diukur melalui hal-hal (1) tidak ada keluhan tentang pelayanan dan produk, (2) perasaan puas pelanggan tentang keseluruhan pelayanan dan produk, dan (3) kesesuaian dengan ekspektasi pelanggan.

Loyalitas pelanggan ditentukan oleh sikap menentukan pilihan tersebut juga untuk membuat komitmen dan melakukan pembelian ulang pada perusahaan 
tersebut (Foster and Cadogan, 2000). Loyalitas pelanggan akan melahirkan 40 perilaku dan tindakan debitur diantaranya (Foster and Cadogan, 2000), (1) perilaku pelanggan yang bersifat memberikan rekomendasi untuk mengajak orang lain untuk melakukan pembelian atau menggunakan produk tersebut, (2) pelanggan akan melakukan aktifitas transaksi atau mempergunakan segala bentuk layanan yang ditawarkan oleh pihak perbankan, (3) pelanggan akan menjadikan perbankan tersebut sebagai pilihan pertama dalam mempergunakan jasa keuangan.

Berdasarkan hasil penelitian terdahulu dan tinjauan pustaka, dapat disusun hipotesis penelitian, (1a) Kualitas layanan berpengaruh signifikan terhadap kepuasan debitur kupedes suku Jawa di BRI unit Bangsalsari, (1b) kualitas layanan berpengaruh signifikan terhadap kepuasan debitur kupedes suku Madura di BRI unit Bangsalsari, (2a) kualitas layanan berpengaruh signifikan terhadap loyalitas debitur kupedes suku Jawa di BRI unit Bangsalsari, (2b) kualitas layanan berpengaruh signifikan terhadap loyalitas debitur kupedes suku Madura di BRI unit Bangsalsari, (3a) kepuasan debitur berpengaruh signifikan terhadap loyalitas debitur kupedes suku Jawa di BRI unit Bangsalsari, (3b) kepuasan debitur berpengaruh signifikan terhadap loyalitas debitur kupedes suku Madura di BRI unit Bangsalsari, (4) komparasi model pengaruh kualitas layanan terhadap kepuasan debitur dan loyalitas debitur kupedes pada suku Jawa dan Madura di BRI unit Bangsalsari. Kerangka konseptual penelitian yang disajikan pada gambar 1 .

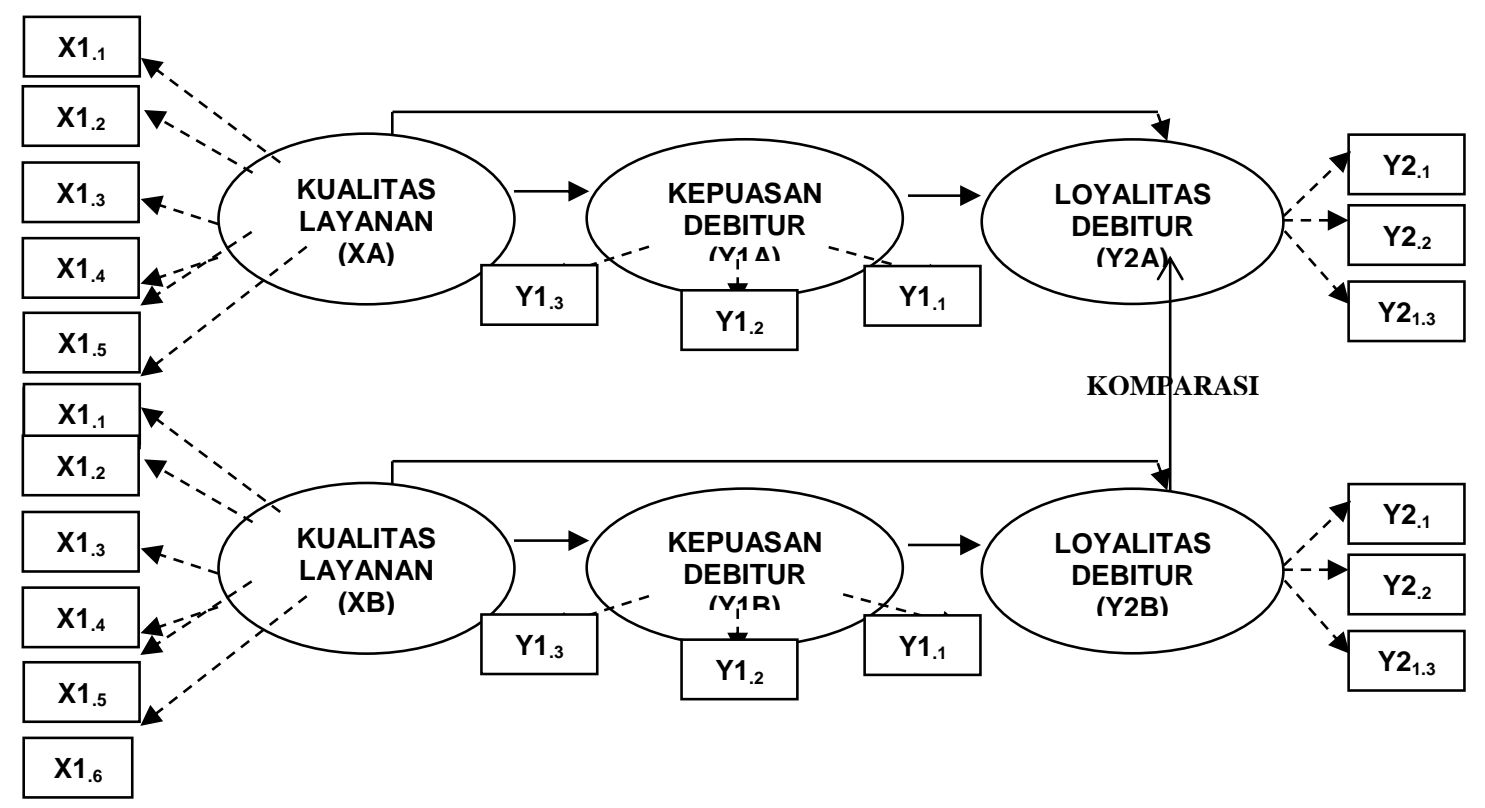

Gambar 1. Kerangka Konseptual Penelitian 


\section{Metodologi}

Rancangan penelitian ini adalah penelitian konfirmatori dengan jumlah populasi 538 debitur kupedes BRI unit Bangsalsari pada posisi tanggal 31 Desember 2016. Penelitian dilakukan di BRI unit Bangsalsari adalah penelitian kuantitatif dengan analisis Structural Equation Model. Penelitian yang mencoba untuk menjelaskan suatu pokok permasalahan dan terdapat sebuah pengujian hipotesa serta melakukan analisis dari data yang diperoleh. Sampel penelitian ditentukan melalui teknik cluster sampling. Pada penelitian ini berjumlah 120 debitur suku Jawa dan 120 debitur suku Madura ditentukan oleh jumlah variabel indikator (12) dikalikan dengan 10 berdasarkan pendapat dari Ferdinand (2006:51) yang menyatakan bahwa ukuran sampel bergantung pada jumlah indikator yang digunakan yaitu sejumlah variabel laten. Jumlah sampel sama dengan jumlah indikator dikalikan 5 sampai 10. Jumlah 120 sampel diambil berdasarkan kriteria mengunakan teknik purposive sampling diantaranya; responden adalah debitur BRI unit Bangsalsari yang menerima kredit kupedes, responden adalah dari suku Jawa dan Madura. Teknik penggunaan sampel terakhir adalah mengkuota untuk pembagian jumlah sampel pada 11 desa yang ada di kecamatan Bangsalsari dari suku Jawa dan Madura.

Variabel yang dianalisa dalam penelitian ini terdiri dari saru variabel eksogen, kualitas layanan. Satu variabel intervening kepuasan debitur dan satu bersifat variabel endogen loyalitas debitur. Kualitas layanan (X1) diukur melalui enam variabel indikator mengacu pada pendapat (Parasuraman, 1988). Kepuasan debitur (Y1) diukur melalui tiga variabel indikator yang mengacu pada pendapat (Pratiwi dan Asih, 2010). Loyalitas debitur yang diukur melalui tiga indikator yang mengacu pendapat dari (Foster and Cadogan, 2000). Tiga variabel diukur dengan menggunakan Skala Likert lima jawaban 1-5. Skala ini adalah skala interval (Indriantoro and Supomo, 2002; Sekaran, 2003). Pengujian hipotesis dilakukan dengan Structural Equation Pemodelan (SEM) dan dilakukan uji komparasi model untuk melihat perbedaan antara dua model pengaruh yang diuji. 


\section{Hasil dan Pembahasan}

Uji Validitas dan Reliabilitas

Tabel 1. Uji validitas dan reliabilitas konstruk suku Jawa

\begin{tabular}{|c|c|c|c|c|c|c|}
\hline \multirow[b]{2}{*}{ No } & \multirow{2}{*}{$\begin{array}{l}\text { Indikator } \\
\text { Variabel }\end{array}$} & \multicolumn{4}{|c|}{ Uji Validitas } & \multirow{2}{*}{$\begin{array}{l}\text { Construct } \\
\text { Reliability }\end{array}$} \\
\hline & & $\begin{array}{l}\text { Loading } \\
\text { Factor }\end{array}$ & C.R & $\mathbf{P}$ & Keterangan & \\
\hline 1. & $\mathrm{X} 1.1$ & 0.579 & 5.960 & 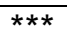 & Valid & \\
\hline 2. & $X 1.2$ & 0.661 & 6.784 & $* * \star$ & Valid & \\
\hline 3. & $\mathrm{X} 1.3$ & 0.771 & 8.099 & $\star \star *$ & Valid & 0.85679 \\
\hline 4. & $\mathrm{X} 1.4$ & 0.651 & 6.918 & $* * *$ & Valid & \\
\hline 5. & $X 1.5$ & 0.808 & 8.562 & $* * *$ & Valid & \\
\hline 6. & $\times 1.6$ & 0.756 & $\star * *$ & *** & Valid & \\
\hline 7. & $\mathrm{Y} 1.1$ & 0.562 & 3.019 & 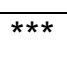 & Valid & \\
\hline 8. & $\mathrm{Y} 1.2$ & 0.907 & 7.785 & $\star \star \star *$ & Valid & 0.81877 \\
\hline 9. & $\mathrm{Y} 1.3$ & 0.831 & $* * *$ & $* * *$ & Valid & \\
\hline 10. & Y2.1 & 0.646 & $\star \star \star *$ & $\star \star \star *$ & Valid & \\
\hline 11. & $Y 2.2$ & 0.611 & 3.787 & $* * *$ & Valid & 0.61251 \\
\hline 12. & $Y 2.3$ & 0.502 & 3.776 & $* * *$ & Valid & \\
\hline
\end{tabular}

Sumber: Data Analisa dengan Amos 5.0

Tabel 2. Uji validitas dan reliabilitas konstruk suku Madura

\begin{tabular}{|c|c|c|c|c|c|c|}
\hline \multirow[b]{2}{*}{ No } & \multirow[b]{2}{*}{$\begin{array}{l}\text { Indikator } \\
\text { Variabel }\end{array}$} & \multicolumn{4}{|c|}{ Uji Validitas } & \multirow{2}{*}{$\begin{array}{c}\text { Constru } \\
\text { ct } \\
\text { Reliabili } \\
\text { ty }\end{array}$} \\
\hline & & $\begin{array}{c}\text { Loading } \\
\text { Factor }\end{array}$ & C.R & $\mathbf{P}$ & Keterangan & \\
\hline 1. & $\mathrm{X} 1.1$ & 0.685 & 2.563 & 0.010 & Valid & \\
\hline 2. & $X 1.2$ & 0.806 & 2.636 & 0.008 & Valid & \\
\hline 3. & $\mathrm{X} 1.3$ & 0.747 & 2.588 & 0.010 & Valid & \\
\hline 4. & $X 1.4$ & 0.650 & 2.528 & 0.011 & Valid & 0.84683 \\
\hline 5. & $X 1.5$ & 0.590 & 2.112 & 0.035 & Valid & \\
\hline 6. & $\mathrm{X} 1.6$ & 0.667 & $\star \star \star *$ & 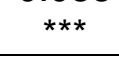 & Valid & \\
\hline 7. & Y1.1 & 0.537 & 5.604 & $\star \star \star$ & Valid & \\
\hline 8. & $\mathrm{Y} 1.2$ & 0.877 & 9.196 & $\star \star \star *$ & Valid & 0.81128 \\
\hline 9. & $\mathrm{Y} 1.3$ & 0.860 & $* * *$ & $* * *$ & Valid & \\
\hline 10. & Y2.1 & 0.749 & 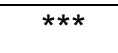 & 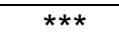 & Valid & \\
\hline 11. & $Y 2.2$ & 0.788 & 5.756 & $* * *$ & Valid & 0.77155 \\
\hline 12. & $Y 2.3$ & 0.642 & 5.247 & $* * *$ & Valid & \\
\hline
\end{tabular}

Sumber: Data Analisa dengan Amos 5.0

Tabel 1 model suku Jawa dan Tabel 2 model suku Madura menunjukkan hasil uji validitas dan reliabilitas dengan analisa faktor konfirmatori yang menunjukkan bahwa semua indikator valid dan reliabel. Ditunjukkan oleh nilai (CR) nilai loading $(C R>1,96)$ pada tingkat probabilitas kurang dari $5 \%$, dan nilai reliabiltas contruct yang direkomendasikan $(\geq 0,60)$.

Tabel 3 terdapat dua jenis suku Jawa dan Madura, pada suku Jawa mayoritas responden adalah laki-laki sebanyak 95 atau 79\%, dan pada suku Madura menunjukkan mayoritas adalah laki-laki sebanyak 100 atau $83 \%$ dari jumlah. 
Tabel 3. Karakteristik responden berdasarkan jenis kelamin

\begin{tabular}{ccc}
\hline & Suku Jawa \\
\hline Jenis Kelamin & Frekuensi & Presentase \\
\hline Laki-laki & 95 & $79 \%$ \\
Perempuan & 25 & $21 \%$ \\
\hline Jumlah & 120 & $100 \%$ \\
\hline \multicolumn{2}{c}{ Suku Madura } \\
\hline Laki-laki & 100 & $83 \%$ \\
\hline Jumpuan & 20 & $17 \%$ \\
\hline
\end{tabular}

Sumber: Data Primer

Tabel 4. Karakteristik responden berdasarkan penggunaan

\begin{tabular}{ccc}
\hline & Suku Jawa & \\
\hline Jumlah Penggunaan & Frekuensi & Presentase \\
\hline 1 kali & 23 & $19 \%$ \\
2 kali & 67 & $56 \%$ \\
Lebih dari 3 kali & 30 & $25 \%$ \\
\hline Jumlah & 120 & $100 \%$ \\
\hline Jumlah Penggunaan & Suku Madura & \\
\hline 1 kali & 16 & Presentase \\
2 kali & 33 & $13 \%$ \\
Lebih dari 3 kali & 71 & $28 \%$ \\
\hline Jumlah & 120 & $59 \%$ \\
\hline
\end{tabular}

Sumber: Data Primer

Pada tabel 4 memberikan informasi penggunaan produk kupedes pada suku Jawa mayoritas menggunakan sebanyak 2 kali sebanyak 67 responden atau 56\%, dan pada suku madura mayoritas menggunakan produk kupedes lebih dari 3 kali sebanyak 71 responden atau 59\% dari total.

Berdasarkan Tabel 5 diketahui bahwa mayoritas responden berlatar belakang profesi wiraswasta pada suku Jawa 72 responden atau 60\%, dan pada suku Madura 81 responden atau $68 \%$ dari total responden. 
Tabel 5. Karakteristik responden berdasarkan profesi

\begin{tabular}{ccc}
\hline & Suku Jawa & \\
\hline Profesi & Frekuensi & Presentase \\
\hline Pegawai Negeri & 11 & $9 \%$ \\
Pegawai Swasta & 26 & $22 \%$ \\
Wiraswasta & 72 & $60 \%$ \\
Angkatan & 5 & $4 \%$ \\
Pensiunan & 6 & $5 \%$ \\
\hline Jumlah & 120 & $100 \%$ \\
\hline Profesi & Suku Madura & \\
\hline Pegawai Negeri & Frekuensi & Presentase \\
Pegawai Swasta & 5 & $4 \%$ \\
Wiraswasta & 31 & $26 \%$ \\
Angkatan & 81 & $68 \%$ \\
Pensiunan & 2 & $2 \%$ \\
Jumlah & 1 & $1 \%$ \\
\hline
\end{tabular}

Sumber: Data Primer

\section{Asumsi dan Uji Kelayakan Model SEM}

Model SEM suku Jawa dan Madura merupakan data multivariat normal, tidak terjadi multikolinieritas atau singularitas, dan tidak terjadi outlier pada data. Hal ini ditunjukkan hasil uji normalitas (CR) memberi nilai model suku Jawa CR 1.148 dan model suku Madura 1.232 terletak diantara $(-1,96 \leq \mathrm{CR} \leq 1,96 \alpha=0,05)$, yang berarti data multivariat normal. Uji multikolinieritas memberikan nilai penentu dari sampel kovarian matrik pada model suku Jawa 21.89, pada suku Madura 31.91. Hasil uji outlier tidak menunjukkan nilai lebih besar dari 12 (indikator) sebesar 21.026, pada suku Jawa sebesar 20.811, dan pada suku Madura 20.972, sehingga dapat disimpulkan tidak ada multivariat outlier dalam penelitian. Hasil uji kesesuaian model menunjukkan model SEM suku Jawa dan Madura. Pada suku Jawa dari delapan model SEM yang diajukan terdapat lima kriteria terpenuhi dan tiga marginal, hasil uji kelayakan adalah $\mathrm{X}_{2}$-chi-square $=113.255 \leq$ pada $\mathrm{df}=95=118.75$ (Baik), Significance Probability $\geq 0.05=0.000$ (Marginal), RMSEA $=0.062 \leq 0.08$ (Baik), GFI $=0.963 \geq 0.90$ (Baik), AGFI $=0.790 \geq 0.90$ (Marginal), CMIN/DF = 2.221 $\leq 3$ (Baik), $\mathrm{TLI}=0.939 \geq 0.90$ (Baik), CFI $=0.875 \geq 0.90$ (Marginal). Uji kelayakan model pada suku Madura dari delapan model SEM yang diajukan terdapat lima kriteria terpenuhi dan tiga marginal, hasil uji kelayakan adalah $\mathrm{X}_{2}$-chi-square $=90.531 \leq$ pada $\mathrm{df}=79=$ 100.749 (Baik), Significance Probability $\geq 0.05=0.000$ (Marginal), RMSEA $=0.060 \leq$ 0.08 (Baik), GFI $=0.904 \geq 0.90$ (Baik), $\mathrm{AGFI}=0.700 \geq 0.90$ (Marginal), CMIN/DF = $2.631 \leq 3$ (Baik), TLI $=0.887 \geq 0.90$ (Marginal), $C F I=0.958 \geq 0.90$ (Baik). 


\section{$\underline{\text { Uji Hipotesis }}$}

Tabel 6. Uji kausalitas model suku Jawa

\begin{tabular}{ccccccc}
\hline \multicolumn{2}{c}{ Hipotesis } & & Estimate & C.R. & P & Keterangan \\
\hline Y1a & $<---$ & $\mathrm{X}$ & 0.174 & 1.420 & 0.155 & Tidak Signifikan \\
Y2a & $<---$ & $\mathrm{X}$ & 0.059 & 3.578 & 0.003 & Signifikan \\
$\mathrm{Y} 2 \mathrm{a}$ & $<---$ & $\mathrm{Y} 1 \mathrm{a}$ & 0.628 & 5.033 & 0.000 & Signifikan \\
\hline
\end{tabular}

Sumber: Analisa data dengan AMOS

Berdasarkan hasil uji hipotesis pada table 6, Hipotesis 1a menyatakan bahwa kualitas layanan memiliki pengaruh signifikan terhadap kepuasan debitur kupedes suku Jawa di BRI unit Bangsalsari tidak diterima. penolakan hipotesis 1a ditunjukkan oleh koefisien jalur positif sebesar 0,174 dengan CR sebesar 1.420 dengan probabilitas ( $p$-value) 0.155 , nilai $p$-value ini lebih besar dibanding tingkat signifikansi (a) yang ditentukan sebesar 0.05. Hal ini mengindentifikasikan bahwa kualitas layanan dari BRI unit Bangsalsari untuk produk kupedes belum dapat diterima dengan baik oleh debitur suku Jawa.Penolakan hipotesis 1a dapat dijelaskan kualitas layanan berpengaruh positif terhadap kepuasan debitur kupedes suku Jawa akan tetapi tidak signifikan, hal tersebut dikarenakan pelayanan yang diberikan diterima dengan baik oleh sebagian debitur suku Jawa tetapi belum menyeluruh kepada debitur suku Jawa lainya.

Berdasarkan hasil uji hipotesis, Hipotesis 2 menyatakan bahwa kualitas layanan memilikipengaruh signifikan terhadap loyalitas debitur kupedes suku jawa di BRI unit Bangsalsari terbukti diterima. Penerimaan hipotesis 2 ditunjukkan oleh koefisien jalur positif sebesar 0.059 dengan CR sebesar 2.578 dengan probabilitas ( $p$-value) 0.003 , nilai $p$-value ini lebih kecil dibanding tingkat signifikansi (a) yang ditentukan sebesar 0.05. Penerimaan hipotesis 2 dapat menjelaskan evaluasi kualitas layanan yang terkait dengan loyalitas debitur kupedes suku Jawa. Kualitas layanan yang positif akan menimbulkan loyalitas debitur yang baik, sedangkan kualitas pelayanan yang negatif akan menimbulkan loyalitas debitur yang negatif.

Berdasarkan hasil uji hipotesis, Hipotesis 3 menyatakan bahwa kepuasan debitur memilikipengaruh signifikan terhadap loyalitas debitur kupedes suku jawa di BRI unit Bangsalsari terbukti diterima. Penerimaan hipotesis 3 ditunjukkan oleh koefisien jalur positif sebesar 0.628 dengan CR sebesar 5.033 dengan probabilitas ( $p$ value) 0.000 , nilai $p$-value ini lebih kecil dibanding tingkat signifikansi (a) yang ditentukan sebesar 0.05 . Penerimaan hipotesis 3 dapat menjelaskan evaluasi kepuasan debitur yang terkait dengan loyalitas debitur kupedes suku Jawa. Kepuasan 
debitur yang positif akan menimbulkan loyalitas debitur yang baik, sedangkan kepuasan debitur yang negatif akan menimbulkan loyalitas debitur yang negatif. Hasil temuan pada penelitian ini sependapat dengan penelitian yang telah dilakukan oleh peneliti terdahulu yang menyatakan kepuasan berpengaruh signifikan terhadap loyalitas.

Tabel 7. Uji kausalitas model suku Madura

\begin{tabular}{ccccccc}
\hline \multicolumn{2}{c}{ Hipotesis } & & Estimate & C.R. & P & Keterangan \\
\hline Y1b & $<---$ & $X$ & 0.914 & 1.615 & 0.106 & Tidak Signifikan \\
Y2b & $<---$ & $X$ & 0.954 & 1.824 & 0.068 & Tidak Signifikan \\
Y2b & $<---$ & Y1b & 0.453 & 3.481 & 0.000 & Signifikan \\
\hline
\end{tabular}

Sumber: Analisa data dengan AMOS

Berdasarkan hasil uji hipotesis, Hipotesis 1b menyatakan bahwa kualitas layanan memilikipengaruh signifikan terhadap kepuasan debitur kupedes suku Madura di BRI unit Bangsalsari tidak diterima. penolakan hipotesis 1b ditunjukkan oleh koefisien jalur positif sebesar 0.914 dengan CR sebesar 1.615 dengan probabilitas ( $p$-value) 0.106 , nilai $p$-value ini lebih besar dibanding tingkat signifikansi (a) yang ditentukan sebesar 0.05. Penolakan hipotesis $1 \mathrm{~b}$ dapat dijelaskan kualitas layanan berpengaruh positif terhadap kepuasan debitur kupedes suku Madura akan tetapi tidak signifikan, hal tersebut dikarenakan pelayanan yang diberikan diterima dengan baik oleh sebagian debitur suku Madura dan belum menyeluruh kepada debitur suku Madura lainya.

Berdasarkan hasil uji hipotesis, Hipotesis $2 \mathrm{~b}$ menyatakan bahwa kualitas layanan memilikipengaruh signifikan terhadap loyalitas debitur kupedes suku Madura di BRI unit Bangsalsari tidak diterima. Penolakan hipotesis $2 \mathrm{~b}$ ditunjukkan oleh koefisien jalur positif sebesar 0.954 dengan $\mathrm{CR}$ sebesar 1.824 dengan probabilitas ( $p$-value) 0.068 , nilai $p$-value ini lebih besar dibanding tingkat signifikansi (a) yang ditentukan sebesar 0.05 . Penolakan hipotesis $2 b$ dapat dijelaskan kualitas layanan berpengaruh positif terhadap loyalitas debitur kupedes suku Madura akan tetapi tidak signifikan, hal tersebut dikarenakan pelayanan yang diberikan diterima dengan baik oleh sebagian debitur suku Madura dan belum menyeluruh kepada debitur suku Madura lainya.

Berdasarkan hasil uji hipotesis, Hipotesis 3b menyatakan bahwa kepuasan debitur memiliki pengaruh signifikan terhadap loyalitas debitur kupedes suku Madura di BRI unit Bangsalsari terbukti diterima. Penerimaan hipotesis 3b ditunjukkan oleh koefisien jalur positif sebesar 0.453 dengan CR sebesar 3.481 dengan probabilitas 
(p-value) 0.000 , nilai $p$-value ini lebih kecil dibanding tingkat signifikansi (a) yang ditentukan sebesar 0.05 . Penerimaan hipotesis $3 \mathrm{~b}$ dapat menjelaskan evaluasi kepuasan debitur yang terkait dengan loyalitas debitur kupedes suku Madura. Kepuasan debitur yang positif akan menimbulkan loyalitas debitur yang baik, sedangkan kepuasan debitur yang negatif akan menimbulkan loyalitas debitur yang negatif.

Terdapat sedikit persamaan dari model yang pertama dengan model yang kedua kualitas layanan yang diberikan oleh karyawan BRI unit Bangsalsari pada debitur suku Madura, memiliki beberapa kekurangan dalam hal pelayanan dalam membentuk kepuasan debitur dan loyalitas debitur walaupun tingkat pengaruhnya tinggi akan tetapi tidak signifikan pada model yang kedua ini.

\section{Kesimpulan}

Berdasarkan hasil pengolahan data dan pembahasan penelitian, maka kesimpulan yang diperoleh adalah: (1) Kualitas layanan berpengaruh secara tidak signifikan terhadap kepuasan debitur kupedes suku Jawa di BRI unit Bangsalsari. Dari pelayanan yang dirasakan debitur suku Jawa hanya sebagian yang puas; (2) Kualitas layanan berpengaruh secara signifikan terhadap loyalitas debitur kupedes suku Jawa di BRI unit Bangsalsari. Pelayanan yang diberikan oleh BRI dalam proses pinjaman modal usaha produk kupedes dalam menciptakan loyalitas debitur terbukti berpengaruh secara signifikan; (3) Kepuasan debitur berpengaruh secara signifikan terhadp loyalitas debitur kupedes suku Jawa di BRI unit Bangsalsari. Kepuasan debitur terbukti berpengaruh terbukti dengan debitur melakukan penggunaan produk kupedes pada frekuensi 2 kali penggunaan sebanyak 67 debitur dan 30 debitur melakukan penggunaan ulang setelah pelunasan sebanyak 30 debitur dari total 120 sampel debitur; (4) Kualitas layanan berpengaruh tidak signifikan terhadap kepuasan debitur kupedes suku Madura di BRI unit Bangsalsari. Hal tersebut didukung dengan lebih sedikit dari suku Madura pada saat pendaftaran ulang dari debitur yang baru sekali melakukan pinjaman kupedes dari suku Madura; (5) Kualitas layanan berpengaruh tidak signifikan terhadap loyalitas debitur kupedes suku Madura di BRI unit Bangsalsari. Dari data penelitian dilapangan hal tersebut dikarenakan debitur suku Madura memperlukan pinjaman modal untuk kelangsungan usahanya; (6) Kepuasan debitur berpengaruh secara signifikan terhadp loyalitas debitur kupedes suku Madura di BRI unit Bangsalsari. Pengambilan data dilapangan didapatkan data bahwa responden suku Madura merasakan puas dan loyal pada produk kupedes 
dikarenakan pada pengajuan selanjutnya pengajuan bisa mencapai 200 juta; dan (7) Komparasi dua model pengaruh debitur suku Jawa dan Madura, pada suku Jawa kualitas layanan masih dapat memiliki pengaruh yang signifikan walaupun kecil, akan tetapi dari komparasi dua model variabel eksogen yaitu kualitas layanan tidak bisa mempengaruhi terbentuknya kepuasan debitur dan loyalitas debitur kupedes suku Jawa dan Madura di BRI unit Bangsalsari.

\section{Saran}

Bagi BRI unit Bangsalsari demi meningkatkan jumlah debitur khususnya kupedes perbaikan pelayanan dari seluruh posisi karyawan yang berada di unit kerja, yang diharapkan dari pemberian pelayanan yang sesuai dengan SOP dapat meningkatkan kepuasan dan loyalitas debitur suku Jawa dan Madura dan suku lain walaupun populasinya sedikit yang berada di kecamatan Bangsalsari.

Penelitian ini Pada suku Jawa pemberian kuisioner dilakukan dengan cara langsung datang kerumah pada saat jam istirahat 12.00 sampai 13.00 Wib, dikarenakan pada saat jam itu para responden suku Jawa sedang istirahat, pada suku Madura penyebaran kuesiner mengalami sedikit kendala, yaitu pada saat penyebaran perlu paham bahasa Madura dari responden, dikarenakan beberapa suku Madura banyak yang buta huruf.

\section{Daftar Referensi}

Bank Indonesia (BI). 2008. Peraturan Bank Indonesia. Tentang Perubahan Atas Peraturan Bank Indonesia Nomor 8/5/PBI/2006 Tentang Mediasi Perbankan. Jakarta.

Bloemer, Josee, Ko de Ruyter \& Pascal Peeters. 1998. Investigating Drivers of Bank Loyalty: The Complex Relationship Between Image, Service, Quality and Satisfaction. International Journal of Bank Marketing. 6(2): 7-8.

Bontis, Nick., \& Lorne D. Booker. 2007. The mediating effect of orgnizational reputation on customer loyalty and service recomendation in banking industry. Management Decion. 45 (9): 1426-1445.

Ferdinand, Augusty. 2006. Structural Equation Modelling Dalam PenelitianManajemen. Edisi 4., Semarang: Badan Penerbit Universitas Diponegoro,

Foster, Brian F Jhon dan W. Cadogan.2000. Relationship Selling and Customer Loyalty., Valoris: Abraham Hawkes

Indriantoro, Nur, dan Bambang, Supomo. 2002. Metodologi Penelitian Bisnis. Edisi Pertama., Yogayakarta: BPFE UGM. 
Lyon, D., Bendall, dan Thomas L. Powers. 2004. The impact of structural and process attributes on satisfaction and behaviour intentions. Journal of Services Marketing. 18 (2): $114-121$.

Oliver, Richard L. 1997. Satisfaction: A Behavioral Perspective on The Consumer. New York: The McGraw-Hill Companies. Inc.

Parasuraman, A. V. A Zeithaml dan LL Berry. 1988. SERVQUAL : A Multiple Item Scale for Measuring Consumer Peceptions of Service Quality. Journal of Retailling. 64(1).

Pratiwi dan Asih. 2010. Perilaku Prososial ditinjau dari Empati dan Kematangan Emosi. Jurnal Psikologi. 1(1): 1-9. 